\title{
KUALITAS REMAJA DI KABUPATEN BANYUMAS
}

\author{
Adolescent Quality in Banyumas District \\ IGNATIUS SUKSMADI ${ }^{1 *}$, UJANG SUMARWAN $^{2}$, ALI KHOMSAN $^{3}$, HARTOYO $^{2}$ \\ ${ }^{1}$ Staf Pengajar Fakultas IImu Sosial dan IImu Politik, Universitas Jendral \\ Soedirman, Jalan HR Bunyamin 993, Grendeng, Purwokerto 53122 \\ ${ }^{2}$ Staf Pengajar Departemen Ilmu Keluarga dan Konsumen, Fakultas Ekologi \\ Manusia, Institut Pertanian Bogor, Jalan Lingkar Kampus IPB Dramaga, \\ Bogor 16680 \\ ${ }^{3}$ Staf Pengajar Departemen Gizi Masyarakat, Fakutas Ekologi Manusia, Institut \\ Pertanian Bogor, Jalan Lingkar Kampus IPB Dramaga, Bogor 16680
}

\begin{abstract}
This research was aimed at analyzing indicator of early adolescent quality and factors affecting the early adolescent quality (EAQ). The study tried to create EAQ index and to analyze its effect to academic achievement. EAQ was measured by body mass index (physical dimension), intelligent quotient and emotional intelligent (nonphysical dimension). The index could show the different quality among public and private school. A crosssectional study was applied on this study. The location were purposively selected at five subdistricts, i.e., Purwokerto, Baturaden, Ajibarang, Rawalo, and Sumpiuh. Total samples of the study were 300 students of secondary school and their families. The sample were divided into public school samples (150 students) and private school samples (150 students). The study created the EAQ categorized in four category, i.e., high (7,7\%), medium (71,3\%), low (20,7\%), and very low (0,3\%). The study described that both student (public and private school) have significant differences on EAQ, academic achievement, school environment. Yet, the study found no significant differences of home environment between public and private school samples. The public school samples had the better EAQ, academic achievement, and school environment than the private school samples. The regression analysis showed that home and school environment, education investment factors affected EAQ. Academic achievement was influenced by EAQ, parent's control on student time, school condition, student activity involvement, family monetary investment, year of schooling of mother, and student expectation.
\end{abstract}

Key words: academic achievement, early adolescent quality, home environment, school environment, secondary school.

\section{PENDAHULUAN}

Keluarga adalah orang yang bertempat tinggal bersama yang dihubungkan dengan ikatan-ikatan biologis, perkawinan, adat istiadat, atau dengan adopsi (Sussman 1987). Reuter (1989) memberikan batasan keluarga sebagai dua orang atau lebih yang dihubungkan dengan darah, adopsi, perkawinan atau kesepakatan untuk hidup di dalam rumah tangga yang sama. Namun lebih khusus lagi dalam UU No. 10 tahun 1992 dinyatakan bahwa keluarga adalah unit terkecil dalam masyarakat yang terdiri dari suami istri, atau suami-istri dengan anaknya, atau ayah dengan anaknya, atau ibu dengan anaknya (BKKBN 1996). Keberadaan anak dalam keluarga memberikan konsekuensi bagi orang tua untuk mengalokasikan dana dan waktu dalam upaya mendidik dan membesarkan anak agar menjadi manusia yang berkualitas.

Hidayat (1997) mendefinisikan kualitas sebagai gabungan karakteristik yang menentukan derajat kehandalan (degree of excellence). Oleh karena itu, kualitas SDM dapat didefiniskan sebagai gabungan dari karakteristik segenap sumberdaya yang ada dalam diri manusia, mencakup karakteristik fisik, akal, kalbu, dan nafsu yang menentukan 
kehandalan manusia baik sebagai makhluk individu maupun makhluk sosial. Kualitas fisik dicerminkan oleh kesehatan dan ketahanan jasmani yang memungkinkan seseorang dapat hidup sehat, aktif, produktif, dan berumur panjang. Kualitas akal dicerminkan oleh daya pikir atau kecerdasan intelektual. Manusia yang berakal selalu terdorong untuk menggali rahasia alam dan kehidupan, dan dengan itu ilmu pengetahuan dan teknologi (iptek) berkembang. Kualitas kalbu dicerminkan oleh keluhuran budi pekerti, moral dan akhlak. Dengan demikian dalam kualitas anak tersebut mengandung unsur kualitas fisik (jasmani), kualitas akal (kecerdasan intelektual), dan kualitas kalbu (mental spiritual). Dengan demikian kualitas remaja dapat diketahui berdasarkan kualitas fisik, kualitas akal, dan kualitas kalbu.

Soekirman (2002) menyatakan bahwa kualitas SDM usia dewasa tidak dapat dipisahkan dengan kualitas hidup pada usia muda. Kualitas hidup manusia muda tersebut tentunya akan berpengaruh pada kualitas sumber daya manusia di kemudian hari. Kualitas SDM dapat dikaitkan dengan perkembangan siklus hidup manusia sejak dalam kandungan sampai memasuki usia lanjut. Pernyataan tersebut menjadi perhatian karena ada kaitan antara kualitas hidup usia muda dengan usia dewasa. Kualitas hidup manusia muda yang dicerminkan dengan tingginya prevalensi gizi kurang (Basuni 2002), upaya perbaikan gizi kurang menggembirakan (Atmarita et al. 2000), kekurangan gizi berdampak pada IQ rendah (Karsin 2000), dan rendahnya status gizi berhubungan dengan pengetahuan gizi yang rendah (Khomsan 1998), serta keterlambatan mendaftar sekolah menambah permasalahan lemahnya intelektual yang disebabkan oleh kekurangan gizi (Jukes 2002).

Tanda rendahnya performa hasil pendidikan dapat ditunjukkan oleh upaya pemerintah membuat standar kelulusan dengan batas nilai minimal 3,01 $\begin{array}{llll}(2003), \quad 4,01 & \text { (2004), 4,26 (2005) }\end{array}$ (Kusumayanti 2007). Standar nilai ini menjadi bagian upaya meningkatkan kualitas anak remaja. Bahkan ketika kemampuan penguasaan siswa terhadap ilmu dikompetisikan menunjukkan hasil yang rendah. Hasil studi International Educational Achievement (IEA) menunjukkan bahwa kemampuan membaca siswa SD di Indonesia berada di urutan ke-38 dari 39 negara yang diteliti. Sementara penelitian the Third International Mathematics and Science Repeat tahun 1999 menunjukkan kemampuan siswa Sekolah Menengah Pertama (SMP) Indonesia di bidang ilmu pengetahuan alam di urutan ke-32 dan untuk matematika di posisi ke-34 dari 38 negara yang diteliti (Harsono 2003). Bahkan dalam Third International Mathematics and Science Indonesia berada pada kategori below basic (bawah rendah) dari kategori advanced, proficient, dan basic (Phillips 2007). Studi tersebut menunjukkan bahwa kualitas anak SMP di Indonesia dalam bidang pendidikan jauh tertinggal dibandingkan dengan negara lain. Dengan demikian faktor yang menentukan kualitas remaja SMP perlu diketahui sehingga standar nilai kelulusan semakin dapat dicapai dan ditingkatkan.

Kualitas sumberdaya manusia secara umum dapat pula dicerminkan dengan suatu indeks pembangunan manusia atau Human Development Index (HDI). Human Development Index negara Indonesia berturut-turut menduduki posisi 98 dari 174 negara (1998), posisi 109 (2000) (Karsin 2004), posisi 112 dari 174 negara (UNDP 2003), dan menduduki peringkat 111 dari 177 negara (UNDP 2004). Indeks tersebut mengisyaratkan perlunya perhatian untuk meningkatkan kualitas manusia Indonesia. Kualitas manusia tersebut menjadi sangat penting sebagai pertanda keberhasilan pembangunan. Kualitas remaja pun menjadi penting karena merupakan bagian dari kualitas sumberdaya manusia keseluruhan. Bentuk kualitas remaja secara khusus yang merupakan aspek penting sebagai pendorong peningkatan kualitas sumberdaya manusia perlu ditemukan dan diwujudkan.

Tujuan penelitian ini secara umum adalah untuk mengidentifikasi kualitas remaja SMP yang duduk di kelas dua dan faktor-faktor yang mempengaruhinya. Di samping itu, penelitian ini juga bertujuan untuk membuat Indeks Kualitas Remaja, menganalisis faktor-faktor yang berpengaruh terhadap kualitas remaja dan menganalisis faktor-faktor yang berpengaruh terhadap prestasi akademik remaja. 


\section{METODE}

\section{Desain, Tempat, dan Waktu}

Desain penelitian adalah cross sectional survey. Penelitian ini dilaksanakan di Kabupaten Banyumas, Provinsi Jawa Tengah. Ada sebanyak sepuluh sekolah dijadikan sebagai lokasi penelitian, masing-masing 5 sekolah negeri mencakup: (1) SMP Negeri 2 Purwokerto, (2) SMP Negeri 1 Ajibarang, (3) SMP Negeri 1 Rawalo, (4) SMP Negeri 2 Sumpiuh, dan (5) SMP Negeri 2 Sumpiuh, dan 5 sekolah swasta mencakup (1) SMP Diponegoro 8 Rawalo, (2) SMP Muhammadiyah Ajibarang, (3) SMP PGRI Baturaden, (4) SMP Giripuro Sumpiuh, dan (5) SMP Susteran Purwokerto. Pemilihan ke sepuluh sekolah tersebut dilakukan secara purposive didasarkan pada prestasi output terbaik dari masingmasing sekolah (SMP negeri dan swasta) di setiap kecamatan. Pemilihan ini mengunakan data sekunder (data nilai ujian nasional) dari Dinas Pendidikan Banyumas 2005. Alasan penentuan tersebut adalah untuk mengetahui perbedaan kualitas antara SMP negeri dan swasta. Penelitian ini dilaksanakan selama 7 bulan yakni dari bulan Januari sampai Juli 2006.

\section{Contoh Penelitian}

Contoh penelitian ini adalah remaja Sekolah Menengah Pertama kelas 2 (dua) yang ada di Kabupaten Banyumas, Provinsi Jawa Tengah. Setelah dilakukan observasi awal diperoleh data 129 SMP. Kemudian dari 129 sekolah diambil 10 sekolah yang tersebar di 5 kecamatan yang terdiri dari 5 sekolah negeri dan 5 sekolah swasta. Pendataan pada 10 SMP tersebut diperoleh jumlah siswa kelas dua Sekolah Menengah Pertama sebanyak 1.659 siswa. Jumlah contoh pada setiap SMP ditentukan dengan mempertimbangkan kebutuhan minimal analisis statistik yakni 30 contoh. Ke 30 contoh tersebut dipilih secara acak (simple random sampling) di semua kelas berdasarkan daftar keseluruhan siswa kelas dua. Dengan demikian total contoh penelitian ini adalah 300 siswa.

\section{Analisis Data}

Analisis data penelitian dilakukan $t$ - analisis regresi variabel independent dengan dependent. Selain itu, juga dilakukan pembuatan indeks kualitas remaja sebagai kesatuan dari intelligence quotient, kecerdasan emosional, dan status gizi remaja. Status gizi remaja dilakukan dengan antropometri. Sedangkan pembuatan indeks kualitas remaja ditempuh dengan menjumlah ketiga indeks tersebut kemudian dibagi tiga.

\section{HASIL DAN PEMBAHASAN}

\section{Karakteristik Contoh dan Keluarga}

Penelitian ini mengambil contoh sejumlah 300 siswa yang terdiri dari siswa laki-laki $(51,7 \%)$ dan perempuan $(48,3 \%)$ (Tabel 1). Komposisi jenis kelamin ini tidak jauh berbeda antara sekolah negeri dan swasta.

Tabel 1. Sebaran jenis kelamin contoh berdasarkan status sekolah

\begin{tabular}{lrrrrrr}
\hline \multirow{2}{*}{$\begin{array}{c}\text { Jenis } \\
\text { Kelamin }\end{array}$} & \multicolumn{2}{c}{ Negeri } & \multicolumn{2}{c}{ Swasta } & \multicolumn{2}{c}{ Total } \\
\cline { 2 - 7 } & $\mathbf{n}$ & $\boldsymbol{\%}$ & $\mathbf{n}$ & $\boldsymbol{\%}$ & $\mathbf{n}$ & $\%$ \\
\hline Laki-Laki & 79 & 52,7 & 76 & 50,7 & 155 & 51,7 \\
Perempuan & 71 & 47,3 & 74 & 49,3 & 145 & 48,3 \\
\hline Total & 150 & 100 & 150 & 100 & 300 & 100 \\
\hline
\end{tabular}

Beberapa karakteristik contoh menunjukkan adanya perbedaan antara sekolah negeri dan swasta yang mencakup nilai ujian akhir nasional, kecerdasan intelektual, kecerdasan emosional, kualitas remaja, prestasi akademis, dan harapan siswa terhadap guru $(p<0,01)$ (Tabel 2). Uji-t tersebut sebagai upaya untuk melihat adanya perbedaan antara sekolah negeri dan swasta dalam masing-masing variabel (Muijs 2004).

Tabel 2. Karakteristik contoh

\begin{tabular}{lrrrr}
\hline \multicolumn{1}{c}{ Variabel } & \multicolumn{3}{c}{ Rataan } & P value \\
\cline { 2 - 4 } & Negeri & $\begin{array}{c}\text { Swas- } \\
\text { ta }\end{array}$ & Total & \\
\hline $\begin{array}{l}\text { Nilai Ujian } \\
\text { Nasional SD }\end{array}$ & 36,36 & 28,92 & 32,64 & $0,000^{\star *}$ \\
$\begin{array}{l}\text { Kecerdasan } \\
\text { intelektual }\end{array}$ & 119,00 & 106,79 & 112,89 & $0,000^{\star *}$ \\
$\begin{array}{l}\text { Kecerdasan } \\
\text { emosi }\end{array}$ & 63,95 & 59,80 & 61,88 & $0,001^{\star *}$ \\
$\begin{array}{l}\text { Status gizi } \\
\text { Kualitas remaja }\end{array}$ & 19,24 & 19,01 & 19,12 & 0,507 \\
$\begin{array}{l}\text { Prestasi } \\
\text { akademis }\end{array}$ & 60,80 & 55,95 & 58,37 & $0,000^{\star *}$ \\
$\begin{array}{l}\text { remaja } \\
\text { Harapan siswa }\end{array}$ & 7,36 & 6,65 & 7,01 & $0,000^{\star *}$ \\
terhadap guru & 77,98 & 70,43 & 74,21 & $0,000^{\star *}$ \\
\hline
\end{tabular}
test untuk menentukan uji beda dan 
Karakteristik keluarga yang dianalisis dalam penelitian ini mencakup lama pendidikan ayah dan ibu, pendapatan keluarga, dan pengeluaran pendidikan contoh. Pendidikan ayah dan ibu menunjukkan adanya perbedaan antara sekolah negeri dan swasta $(p<0,01)$. Pendidikan ayah dan ibu contoh yang berasal dari sekolah negeri mempunyai rataan yang lebih tinggi. Hal ini menunjukkan tingkat pendidikan ayah dan ibu contoh dari sekolah negeri secara nyata jauh lebih baik. Namun, pendapatan keluarga dan pengeluaran pendidikan untuk contoh tidak ada perbedaan antara contoh dari sekolah negeri dan swasta $(p>0,01)$ (Tabel 3).

Tabel 3. Karakteristik keluarga

\begin{tabular}{|c|c|c|c|c|}
\hline \multirow{2}{*}{ Variabel } & \multicolumn{3}{|c|}{ Rataan } & \multirow{2}{*}{$\begin{array}{c}\mathbf{P} \\
\text { value }\end{array}$} \\
\hline & Negeri & Swasta & Total & \\
\hline $\begin{array}{l}\text { Lama pend. } \\
\text { ayah (tahun) }\end{array}$ & 12,94 & 11,23 & 12,09 & $0,000^{\star \star}$ \\
\hline $\begin{array}{l}\text { Lama pend. } \\
\text { ibu (tahun) }\end{array}$ & 12,31 & 10,65 & 11,48 & $0,000^{* \star}$ \\
\hline $\begin{array}{l}\text { Pdptn } \\
\text { (rupiah/bln) }\end{array}$ & $\begin{array}{r}343.023 \\
40\end{array}$ & $\begin{array}{r}362.219 \\
, 58\end{array}$ & $\begin{array}{l}352.6 \\
21,49\end{array}$ & 0,661 \\
\hline $\begin{array}{l}\text { Pengel. } \\
\text { pend. contoh } \\
\text { (rupiah/bln) }\end{array}$ & $\begin{array}{r}138.043 \\
33\end{array}$ & $\begin{array}{r}148.834 \\
, 00\end{array}$ & $\begin{array}{l}143.4 \\
38,67\end{array}$ & 0,429 \\
\hline
\end{tabular}

Karakteristik lingkungan keluarga contoh mencakup dorongan berprestasi, apirasi pendidikan, fasilitas belajar, pemanfaatan waktu, dan ikatan keluarga. Semua variabel tersebut menunjukkan tidak adanya perbedaan antara contoh dari sekolah negeri dan swasta $(p>0,01)$ (Tabel 4).

Tabel 4. Karakteristik lingkungan keluarga

\begin{tabular}{|c|c|c|c|c|}
\hline \multirow{2}{*}{ Variabel } & \multicolumn{3}{|c|}{ Rataan } & \multirow{2}{*}{$\begin{array}{c}P \\
\text { value }\end{array}$} \\
\hline & Negeri & Swasta & Total & \\
\hline $\begin{array}{l}\text { Lingkungan } \\
\text { keluarga }\end{array}$ & 61,48 & 60,89 & 61,19 & 0,546 \\
\hline $\begin{array}{l}\text { Dorongan } \\
\text { berprestasi }\end{array}$ & 73,77 & 73,65 & 73,71 & 0,926 \\
\hline $\begin{array}{l}\text { Aspirasi } \\
\text { pendidikan }\end{array}$ & 71,23 & 69,45 & 70,34 & 0,114 \\
\hline $\begin{array}{l}\text { Fasilitas } \\
\text { belajar }\end{array}$ & 51,22 & 51,30 & 51,26 & 0,961 \\
\hline $\begin{array}{l}\text { Pemanfaata } \\
\text { n waktu }\end{array}$ & 55,87 & 58,67 & 57,27 & 0,020 \\
\hline $\begin{array}{l}\text { Ikatan } \\
\text { keluarga }\end{array}$ & 57,38 & 54,57 & 55,97 & 0,019 \\
\hline
\end{tabular}

\section{Karakteristik Lingkungan Sekolah}

Karakteristik sekolah dalam penelitian ini mencakup peranan guru, aktivitas siswa, kondisi sekolah, dan iklim belajar. Tabel 5 memuat perhitungan mengenai perbedaan lingkungan sekolah antara sekolah negeri dan swasta. Secara umum lingkungan sekolah menunjukkan adanya perbedaan antara sekolah negeri dan swasta $(p<0,01)$. Begitu pula aktivitas siswa dan kondisi sekolah menunjukkan adanya perbedaan $(p<0,01)$. Namun untuk peranan guru dan iklim belajar tidak menunjukkan adanya perbedaan $(p>0,01)$.

Tabel 5. Karakteristik lingkungan sekolah

\begin{tabular}{lcccc}
\hline \multicolumn{1}{c}{ Variabel } & \multicolumn{3}{c}{ Rataan } & $\begin{array}{c}\text { P } \\
\text { value }\end{array}$ \\
\cline { 2 - 4 } & Negeri & Swasta & Total & valungan \\
Lingkungan & 70,36 & 67,42 & 68,89 & $0,003^{\star *}$ \\
sekolah & 70,10 & 68,43 & 69,27 & 0,175 \\
Peranan guru & 72,68 & 69,07 & 70,88 & $0,003^{\star *}$ \\
Aktivitas & & & & \\
siswa & 70,45 & 64,45 & 67,45 & $0,000^{\star *}$ \\
Kondisi & 67,07 & 67,36 & 67,21 & 0,830 \\
sekolah & & & &
\end{tabular}

\section{Identifikasi Kualitas Remaja}

Kualitas remaja merupakan suatu kesatuan dari aspek fisik dan non fisik. Hidayat (1997) mendefinisikan kualitas sebagai gabungan karakteristik yang menentukan derajat kehandalan (degree of excellence). Oleh karena itu, kualitas SDM dapat didefinisikan sebagai gabungan dari karakteristik segenap sumberdaya yang ada dalam diri manusia, mencakup karakteristik fisik, akal, kalbu, dan nafsu yang menentukan kehandalan manusia baik sebagai makhluk individu maupun makhluk sosial. Ketiga aspek dalam kualitas remaja tersebut mencakup status gizi (kualitas fisik), kecerdasan emosional (kualitas kalbu), dan kecerdasan intelektual (kualitas akal). Indeks Kualitas Remaja yang dibangun dari tiga aspek tersebut, digambarkan dalam Gambar 1.

Indeks Kualitas Remaja (IKR) mencakup Indeks Kecerdasan Intelektual (IQ), Indeks Kecerdasan Emosional (EI), dan Indeks Status Gizi (IMT). Indeks Status Gizi (IMT) sebagai ukuran kualitas fisik dihitung dengan rumusan sebagai berikut:

IKR $=\underline{\text { INDEKSIQ + INDEKSEI +INDEKSSTATUSGIZIIIMT) }}$ 


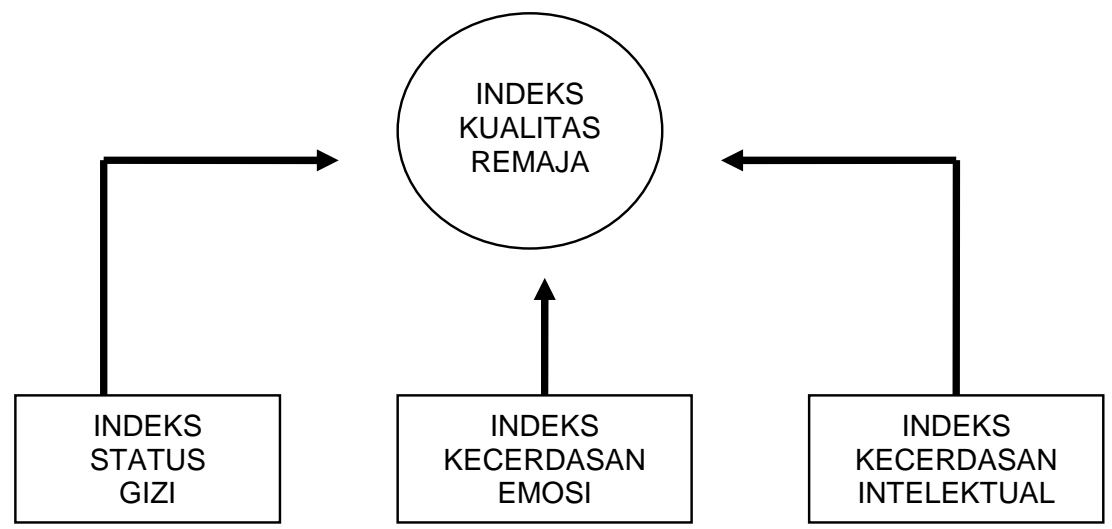

Gambar 1. Indeks kualitas remaja terdiri dari faktor fisik (indeks status gizi) dan faktor non fisik (kecerdasan emosi dan intelektual)

Hasil perhitungan indeks kualitas remaja disederhanakan dalam bentuk kategori. Kategori kualitas remaja dibagi menjadi empat kategori, yaitu: tinggi, sedang, rendah, dan sangat rendah. Indeks kualitas remaja mempunyai indeks terendah dan tertinggi adalah 20,94 dan 84,23 . Kemudian indeks tersebut dibagi menjadi keempat kategori didasarkan pada nilai indeks maksimal adalah 100 sehingga pembagian indeks tersebut ditentukan dengan interval 25 sebagai berikut: tinggi (75,01-100), sedang (50,01-75,00), rendah (25,01-50,00), sangat rendah $(0-25,00)$ sebagaimana tersaji pada Tabel 6 .

Tabel 6. Sebaran kategori indeks kualitas remaja berdasarkan status sekolah

\begin{tabular}{lrrrrrr}
\hline \multirow{2}{*}{ Kategori } & \multicolumn{2}{c}{ Negeri } & \multicolumn{2}{c}{ Swasta } & \multicolumn{2}{c}{ Total } \\
\cline { 2 - 7 } & \multicolumn{1}{c}{ n } & \multicolumn{1}{c}{ n } & \% & \multicolumn{1}{c}{ n } & \multicolumn{1}{c}{$\%$} \\
\hline Tinggi & 16 & 10,7 & 7 & 4,7 & 23 & 7,7 \\
Sedang & 109 & 72,7 & 105 & 70,0 & 214 & 71,3 \\
Rendah & 24 & 16,0 & 38 & 25,3 & 62 & 2,7 \\
Sangat & 1 & 0,7 & 0 & 0,0 & 1 & 0,3 \\
rendah & 150 & 100 & 150 & 100 & 300 & 100 \\
\hline \multicolumn{1}{c}{ Jumlah } & 150
\end{tabular}

Model Faktor-faktor yang Berpengaruh terhadap Indeks Kualitas Remaja

Kualitas remaja dipengaruhi oleh lingkungan keluarga dan sekolah, serta investasi pendidikan sebagaimana dalam model (Tabel 7). Model kualitas remaja tersebut menunjukkan faktor yang signifikan $(p<0,01$ dan $p<0,05)$ dan faktor yang tidak signifikan $(p>0,05)$. Hasil penelitian ini menunjukkan bahwa faktor yang signifikan berpengaruh terhadap kualitas remaja adalah jenis kelamin $(p<0,05)$, status sekolah $(p<0,05)$, lingkungan keluarga $(p<0,05)$, serta lingkungan sekolah $(p<0,01)$. Sementara itu, faktor yang tidak signifikan adalah status kerja ibu, keluarga luas/inti, kategori sejahtera, nilai anak, umur ibu, jumlah anggota keluarga, morbiditas, pendampingan belajar ibu, pekerjaan ibu

Tabel 7. Analisis regresi faktor-faktor yang berpengaruh terhadap kualitas remaja

\begin{tabular}{lcc}
\hline \multicolumn{1}{c}{ Peubah Bebas } & $\begin{array}{c}\text { Koefisien } \\
\text { Distanda- } \\
\text { risasi } \\
\text { (Beta) }\end{array}$ & Sig. \\
\hline Status kerja ibu & $-0,032$ & 0,577 \\
Keluarga luas/inti & $-0,022$ & 0,705 \\
Jenis kelamin & $-0,115$ & 0,035 \\
Status sekolah & $-0,164$ & 0,004 \\
Kategori sejahtera & 0,015 & 0,792 \\
Lingkungan keluarga & 0,124 & 0,045 \\
Lingkungan sekolah & 0,223 & 0,000 \\
Nilai Anak & 0,005 & 0,929 \\
Umur ibu & $-0,028$ & 0,613 \\
Jumlah angggota & 0,034 & 0,566 \\
keluarga & $-0,027$ & 0,649 \\
Morbiditas & $-0,040$ & 0,491 \\
Mendampingi anak & \multicolumn{2}{c}{0,170} \\
belajar (ibu) & 0,089 & 0,901 \\
Kerja rumah (Ibu) & 0,008 & 0,385 \\
Sikap Gizi & 0,062 & 0,029 \\
Lama pendidikan ibu & \multicolumn{2}{c}{0,145} \\
Investasi pendidikan & \multicolumn{2}{c}{0,486} \\
untuk contoh & \multicolumn{2}{c}{0,193} \\
\hline R & \multicolumn{2}{c}{0,00} \\
Adjusted R Square & \multicolumn{2}{c}{0} \\
Signifikansi & \multicolumn{2}{c}{0,0} \\
\hline
\end{tabular}


di rumah, sikap gizi ibu, dan lama pendidikan ibu. Namun untuk lama pendidikan ibu dapat dikatakan signifikan apabila digunakan batas taraf signifikasi $0,1 \quad(p<0,1)$. Analisis model tersebut menunjukkan hasil signifikan $p<0,01$. Model ini mempunyai adjusted $R$ square sebesar 0,193 artinya bahwa kualitas remaja dapat dijelaskan sebesar 19,3\% oleh varian, sedangkan sisanya sebesar $80,7 \%$ dijelaskan di luar varian tersebut.

Keluarga merupakan institusi dimana anak mengalami tumbuh dan berkembang. Borkowsky et al. (2002) dalam Aufseer et al. (2006) mengemukakan bahwa para orang tua membentuk kehidupan anak-anak mereka sejak bayi sampai dengan dewasa. Hasil penelitian Vandivere et al. (2000) menunjukkan bahwa lingkungan anak-anak erat berkaitan dengan perilaku dan kesejahteraan remaja di tempat tinggal mereka dan lingkungan-lingkungan dimana anak-anak tersebut tinggal berpengaruh terhadap kesejahteraan (kesehatan dan kebahagiaan) mereka. Keluarga menyediakan segala kebutuhan untuk anak agar dapat berkembang fisik dan nonfisik mereka. Kebutuhan fisik dicukupi dengan kebutuhan asupan pangan yang memadai agar memperoleh gizi yang memadai sehingga pertumbuhan fisik dapat normal. Namun, lebih dari sepertiga $(36,1 \%)$ anak usia sekolah di Indonesia tergolong pendek ketika memasuki usia sekolah yang merupakan indikator adanya kurang gizi kronis (Hadi 2005). Anak yang menderita kurang gizi berat mempunyai rata-rata IQ 11 poin lebih rendah dibandingkan rata-rata anakanak yang tidak kurang gizi berat.

Frydenberg (1997) mengungkapkan bahwa keluarga, dan sekolah merupakan pelaku-pelaku utama untuk sosialisasi guna meningkatkan perbaikan segi kesehatan dan psikologis. Stratton dan Reid (2004) menunjukkan hasil penelitian bahwa emosi, penyesuaian perilaku dan sosial anak-anak merupakan masalah penting untuk keberhasilan sekolah karena ada kesiapan pengetahuan dan akademis. Anak-anak yang memiliki kesulitan memusatkan perhatian, mengikuti pengarahan guru, bergaul dengan anak-anak lainnya, dan mengendalikan emosi yang negatif mempunyai kinerja yang rendah di sekolahan. $\begin{array}{lcr}\text { Lingkungan } & \text { sekolah } & \text { merupakan } \\ \text { lingkungan dimana } & \text { anak-anak } \\ \text { meluangkan banyak } & \text { waktu untuk }\end{array}$ berinteraksi dengan para guru dan siswa lain. Lingkungan sekolah menjadi penting untuk perkembangan kompetensi emosi dan kesehatan mental anak. Garmezi (1991) dalam Pahl dan Barret (tt) mengemukakan bahwa kompetensi emosi sosial dilihat sebagai faktor proteksi yang penting bagi anak-anak muda, melindungi mereka dari tekanan-tekanan, dan mencegah perkembangan masalah emosi sosial dan perilaku yang bermasalah di kemudian hari. Marin dan Brown (2008) mengemukakan bahwa lingkungan sekolah juga dapat berpengaruh langsung terhadap kesehatan para siswa. Para siswa di lingkungan sekolah yang berbahaya banyak terlibat pada perkelahian, menjadi terluka/korban, dan mengalami tekanan emosional. Lingkungan sekolah yang berbahaya tersebut tentunya mempengaruhi perkembangan para siswa menjadi kurang baik.

\section{Model Faktor-faktor yang Berpengaruh terhadap Prestasi Akademik Remaja Prestasi akademik remaja} merupakan hasil pencapaian nilai pada satu atau seluruh mata pelajaran yang diajarkan di sekolah tersebut. Ada 6 mata pelajaran yang digunakan sebagai penilaian yaitu: Matematika, Bahasa Inggris, Bahasa Indonesia, IImu Pengetahuan Alam, IImu Pengetahuan Sosial, dan PPKn. Kesemua nilai mata pelajaran tersebut diakumulasikan sehingga menjadi rata-rata nilai prestasi akademik. Model prestasi akademik menunjukkan faktor yang signifikan $(p<0,01$ dan $p<0,05)$. Faktor-faktor yang signifikan mencakup kualitas remaja, pemanfaatan waktu, kondisi sekolah, aktivitas siswa, pengeluaran pendidikan, lama pendidikan ibu, dan harapan siswa terhadap guru. Analisis model tersebut menunjukkan hasil signifikan $p<0,01$. Model ini mempunyai adjusted $R$ square sebesar 0,407 artinya bahwa kualitas remaja dapat dijelaskan sebesar 40,7\% oleh varian, sedangkan sisanya sebesar $59,3 \%$ dijelaskan di luar varian tersebut (Tabel 8). 
Tabel 8. Analisis regresi faktor-faktor yang berpengaruh terhadap prestasi akademik remaja

\begin{tabular}{|c|c|c|}
\hline Variabel & $\begin{array}{c}\text { Koefisien } \\
\text { distandarisasi } \\
\text { (Beta) }\end{array}$ & Sig. \\
\hline Kualitas remaja & 0,137 & 0,008 \\
\hline Ikatan keluarga & $-0,050$ & 0,405 \\
\hline Pemanfaatan waktu & $-0,139$ & 0,010 \\
\hline Fasilitas belajar & $-0,028$ & 0,640 \\
\hline $\begin{array}{l}\text { Aspirasi pendidikan } \\
\text { dan pekerjaan }\end{array}$ & 0,040 & 0,491 \\
\hline $\begin{array}{l}\text { Dorongan } \\
\text { berprestasi }\end{array}$ & $-0,031$ & 0,608 \\
\hline Iklim belajar & $-0,107$ & 0,086 \\
\hline Kondisi sekolah & 0,150 & 0,012 \\
\hline Aktivitas siswa & 0,107 & 0,042 \\
\hline Guru & $-0,092$ & 0,107 \\
\hline $\begin{array}{l}\text { Pengeluaran } \\
\text { pendidikan }\end{array}$ & 0,222 & 0,000 \\
\hline $\begin{array}{l}\text { Mendamping anak } \\
\text { belajar (ibu) }\end{array}$ & $-0,027$ & 0,561 \\
\hline $\begin{array}{l}\text { Lama pendidikan } \\
\text { ibu }\end{array}$ & 0,296 & 0,000 \\
\hline $\begin{array}{l}\text { Harapan siswa thd } \\
\text { guru }\end{array}$ & 0,233 & 0,000 \\
\hline $\mathrm{R}$ & 0,659 & \\
\hline Adjusted R Square & 0,407 & \\
\hline Signifikan & 0,000 & \\
\hline
\end{tabular}

Kualitas remaja (IQ, EI, SG) mempunyai pengaruh yang signifikan terhadap prestasi akademik remaja. Kecerdasan intelektual (Intelligence Quotient) merupakan faktor yang menjadi prediktor dapat berpengaruh terhadap prestasi belajar (educational achievement) (Anonim 2007), kesejahteraan national (Whetzel \& McDaniel 2006), ekologi dan pendidikan (Barber 2005), pertumbuhan ekonomi (Ram 2007), educational attainment (Lynn \& Mikk 2006), dan kreativitas siswa (Olatoye \& Oyundoyin 2007). Kecerdasan emosi menjadi prediktor terhadap prestasi akademik para siswa (Samra 2000), performance optimum siswa (Culver \& Yokomoto 1999), academic success (Parker 2003), academic achievement dan test performance (Low \& Nelson 2004), academic achievement (Abisamra 2000), academic performance (Cotton \& Wikelund 1989), serta prestasi akademik (Vela 2003). Sementara itu, status gizi menjadi prediktor terhadap prestasi akademik siswa (Florencio 1995, Zaini et al. 2005).

Selain itu, kondisi sekolah dan pengeluaran pendidikan berpengaruh signifikan juga terhadap prestasi akademis remaja. Kondisi sekolah memberikan pengaruh positif terhadap prestasi akademik siswa (Young et al 2003). Aktivitas siswa mempunyai pengaruh terhadap prestasi akademik siswa (Fung \& Wong 1991, Galiher 2006, Eccles et al. 2003, dan Moriana et al. 2006). Pengeluaran pendidikan berpengaruh terhadap prestasi akademik siswa (Jenkins SP \& Schluter C 2002, Aakvik et al. 2005, Khayyer 1997, Arvilommi 2003).

Begitu pula faktor siswa berpengharapan baik terhadap para guru mereka mempunyai prestasi akademik yang baik. Ekspektasi dapat diartikan juga dengan harapan atau keyakinan bahwa sesuatu akan terjadi atau seseorang akan memperoleh sebagaimana yang diharapkan (Collins 2003). Hal ini sebagaimana digambarkan oleh Leigh dan Mead (2005) bahwa pengetahuan guru terhadap materi khusus, teristimewa di jenjang pendidikan sekolah menengah pertama, merupakan prediktor yang baik terhadap prestasi belajar anak. Harapan siswa terhadap penguasaan guru terhadap materi khusus tersebut merupakan orientasi maju para siswa terhadap materi khusus yang dikuasai oleh guru atau para guru. Oleh karena itu para siswa yang mempunyai harapan baik terhadap para guru mereka mempunyai prestasi akademik yang baik. Schilling dan Schilling (1999) dalam Miller (2001) mengungkapkan bahwa ekspektasi membentuk pengalaman pembelajaran yang begitu berdaya guna. Ekspektasi mampu meningkatkan kinerja dimana seseorang yang mempunyai harapan yang tinggi maka mempunyai kinerja/prestasi yang tinggi, dan seseorang dengan ekspektasi yang tinggi menampilkan level kinerja/prestasi yang lebih tinggi dibandingkan dengan yang berpengharapan rendah, bahkan meskipun mereka dalam keadaan kemampuan yang sama.

\section{KESIMPULAN DAN SARAN}

\section{Kesimpulan}

Hasil penelitian ini menunjukkan adanya perbedaan baik siswa maupun keluarga sekolah negeri dan swasta. Perbedaan secara signifikan tersebut mencakup nilai ujian akhir nasional, 
kecerdasan intelektual (IQ), kecerdasan emosi (EI), lingkungan sekolah, kondisi sekolah, aktivitas siswa, harapan siswa terhadap guru, lama pendidikan ayah, lama pendidikan ibu, pendapatan, kualitas remaja, prestasi akademis remaja. Adapun yang tidak menunjukkan adanya perbedaan adalah pemanfaaan waktu, lingkungan keluarga, pengeluaran pendidikan, dan nilai mata pelajaran ilmu pengetahuan sosial. Indeks kualitas remaja menunjukkan kategori tinggi $(7,7,0 \%)$, sedang $(71,3 \%)$, rendah $(20,7 \%)$, dan sangat rendah $(0,3 \%)$. Kualitas remaja dipengaruhi oleh lingkungan keluarga dan sekolah. Sementara itu, prestasi akademis remaja dipengaruhi oleh kualitas remaja, pemanfaatan waktu, kondisi sekolah, aktivitas siswa, pengeluaran pendidikan, lama pendidikan ibu, dan harapan siswa terhadap guru.

\section{Saran}

Hasil penelitian ini dapat menjadi sumbang saran dalam upaya meningkatkan kualitas remaja dalam bidang pendidikan. Peningkatan kualitas remaja dapat dilakukan melalui lingkungan keluarga dan lingkungan sekolah. Lingkungan keluarga merupakan institusi yang dapat memberikan dorongan untuk berprestasi, mempunyai aspirasi pendidikan dan pekerjaan, menyediakan fasilitas belajar, mengontrol pemanfaatan waktu, dan menciptakan ikatan keluarga. Begitu pula lingkungan sekolah dapat meningkatkan kualitas remaja melalui peningkatan kompetensi guru dan aktivitas siswa. Peningkatan kualitas remaja dan prestasi akademik tersebut merupakan langkah yang penting agar dapat mendukung peningkatan kualitas sumberdaya manusia Indonesia.

\section{DAFTAR PUSTAKA}

Aakvik, Salvanes, Vaage. 2005. Educational Attainment and Family Background. Centre for Economic Studies in Social Insurance. Departement of Economics. University of Bergen. [terhubung berkala]. http://www. econ.uib.no/filer/1330.pdf

Abisamra NS. 2000. The Relationship between Emotional Intelligence and Academic Achievement in Eleventh
Graders. Auburn University at Montgomery, Research in Education, FED 661. [terhubung berkala]. http://nadabs.tripod.com/researchintell2.html [3 Mar 2000].

Anonim. 2007. Intelligence Quotient. [terhubung berkala]. http://en.wikipedia.org/wiki/intelligenc equotient. [15 Juni 2007].

Arvilommi TO. 2003. Pupils Achievement Strategies, Family Background and School Performance. University of Helsinki, Departement of Psychology, Research Reports No: 23.

Atmarita $A B$, Dini L, Soekirman, Tilden RL. 2000. The Effect of Economic Crisis on The Nutritional Status of Indonesian Pre-School Children. Gizi Indonesia. Journal of the Indonesian Nutrition Association. Persatuan Gizi Indonesia. Vol. XXIV.

Aufseeser et al. 2006. The Family Environment and Adolescent Wellbeing: Exposure to Positive and Negative Family Influences. Washington, D.C.: Child Trends; and San Francisco, CA: National Adolescent Health Information Center, University of California, San Francisco.

Basuni JA, Sumarno I. Status Gizi Penduduk Indonesia. Majalah Pangan No. 38/XI/Jan/2002. Jakarta: Puslitbang Bulog.

Barber N. 2005. Educational and Ecological Correlates of IQ: A Crossnational Investigation. Intelligence 33 (2005) 273-284. http://www.science direct.com

[BKKBN] Badan Koordinasi Keluarga Berencana Nasional. 1996. Panduan Pembangunan Keluarga Sejahtera Dalam Rangka Penanggulangan Kemiskinan. Jakarta: Kantor Menteri Negara Kependudukan.

Borkowsky J, Ramey S, Bristol-Power M, editor. 2002. Parenting and the child's world: Influences on academic, intellectual, and socialemotional development. Dalam Aufseeser, Dena, Susan Jekilek, dan Brett Brown. 2006. The Family Environment and Adolescent WellBeing: Exposure to Positive and Negative Family Influences. Washington, D.C.: Child Trends; and San Francisco, CA: National 
Adolescent Health Information Center, University of California, San Francisco.

Collins Cobuild English Dictionary for Advanced Learners $4^{\text {th }}$ edition published in 2003.

Cotton K, Wikelund K. 1989. Parent Involvement in Education. School Improvement Research Series. [terhubung berkala]. http://educationnorthwest.org/webfm send/567.

Eccles JS, Barber BL, Stone M, Hunt J. 2003. Extracurricular Activities and Adolescent Development. [terhubung berkala]. Journal of Social Issues. Volume 59 Issue 4 December 2003. http://www3.interscience.wiley.com/jo urnal/

Florencio CA. 1995. Child, School, Home Determinants of Academic Performance. Eduksyon (Vol. 1 No. 2. April - June 1995) A Quarterly Monograph Series of the UP Education Research Program.

Frydenberg E. 1997. Adolescent Coping: Theoritical and Research. Adolescence and Society Series. Routledge. London.

Fung Y, Wong N. 1991. Involvement in Extracurricular Activities as Related to Academic Performance, Personality, and Peer Acceptance. Educational Journal 19: 155-160.

Galiher S. 2006. Understanding the Effect of Extracurricular Involvement. A Research Project Report Presented to the School of Education Indiana University South Bend.

Hadi H. 2005. Beban Ganda Masalah Gizi dan Implikasinya terhadap Kebijakan Pembangunan Kesehatan Nasional. Pidato Pengukuhan Jabatan Guru Besar pada Fakultas Kedokteran Unversitas Gadjah Mada [5 Februari 2005].

Hidayat S. 1997. Membangun Sumberdaya Manusia Berkualitas Suatu Telaahan Gizi Masyarakat dan Sumber Daya Keluarga. Orasi IImiah Guru Besar IImu Gizi Masyarakat dan Sumberdaya Keluarga. Fakultas Pertanian. Institut Pertanian Bogor [6 September 1997].

Harsono EB. 2003. Pendidikan Indonesia Terburuk di Asia. Suara Pembaruan [7 Mei 2003].
Jenkins SP, Schluter C. 2002. Does low income in early childhood affect adolescent school attainment? Evidence from the German SocioEconomic Panel. [terhubung berkala]. http://www.iser.essex.ac.uk/publicati on/working-paper/iser/2002-20.pdf

Jukes $\mathrm{M}$ et al. 2002. Nutrition and Education in Nutrition: A Foundation for Development. [terhubung berkala] http://acc.unsystem.org.scn/.

Karsin ES. 2004. Klasifikasi Pangan dan Gizi. Dalam Baliwati YF, Khomsan A, Dwiriani CM (ed.) Pengantar Pangan dan Gizi. Jakarta: Penebar Swadaya.

Khayyer. 1997. A Study of the Relationship Between Some Socioeconomic Indexes and the Academic Achievement Among A Group of Freshman High School Students in the New Educational System. Journal of Social Sciences \& Humanities Vol. 12, No. 2, Spring 1997.

Khomsan A, Rustiawan A, Widodo $Y$. 1998. Pengetahuan Gizi dan Perilaku Kesehatan Anak SD dan Orang Tua di Desa IDT Penerima PMT-AS. Gizi Indonesia. Vol. XXIII.

Kusumayanti R. 2007. Unas dari Masa ke Masa. [terhubung berkala]. http://limas.p4tkmatekatika.com. [8 Juni 2007]

Leigh A, Sara M. 2005. Lifting Teacher Performance. Progressive Policy Institute. Policy Report. [terhubung berkala]. www.ppionline.org.

Low GR, Nelson DB. 2003. Emotional Intelligence, Effectively Bridging the Gap Between High School and College. [terhubung berkala]. http://education.tamuk.edu/eiconf/TA SSPEI04.pdf.

Lynn R, Mikk J. 2006. National differences in intelligence and educational attainment. Intelligence 35:115-121.

Marin P, Brett B. 2008. The School Environment and Adolescent WellBeing: Beyond Academics. National Adolescent Health Information Center. [terhubung berkala]. http://www.childtrends.org.

Moriana J et al. 2006. Extracurricular Activities and Academic Performance in Secondary Students. Depaertement of Psychology, School 
of Educational Sciences, University of Cordova. Electronic Journal of Research in Educational Psychology 4: 33-46.

Muijs D. 2004. Doing Quantitative Research in Education. SAGE Publication Inc. London, Thousand Oaks, New Delhi.

Olatoye RA, Oyundoyin JO. 2007. Intelligence Quotient as a Predictor of Creativity Among Some Nigerian Secondary School Student. Educational Research and Review Vol. 2 (4), pp.092-095, April 2007 Available online at http://www. academicjournals.org/ERR ISSN 1990-3839 (C) 2007 Academic Journals

Pahl KM, Paula MB. tanpa tahun. The Development of Social-Emotional Competence in Preschool Aged Children: An Introduction of the Fn FRIENDS Program. Pathways Health and Research Centre, Brisbane. [terhubung berkala]. http://www. ecta.org.au

Parker JDA et al. 2003. Academic Success in High School: Does Emotional Matter? ERIC Clearing House.

Phillip GW. 2007. Expressing International Educational Achievement in Terms of U.S. Performance Standards: Linking NAEP Achievement Levels to TIMSS1. [terhubung berkala]. http://www.air.org.

Ram R. 2007. IQ and Economic Growth: Further Augmentation of MankiwRomer-Weil model. Economic Leters 94: 7-11.

Samra NA. 2000. The Relationship between Emotional Intelligence and Academic Achievement in Eleventh Graders. Auurn University at Montgomery. Research in Education.

Culver R, Yokomoto, Charles. 1999. Optimum Academic Performance and Its Relation to Emotional Intelligence. $29^{\text {th }} \quad$ ASEE/IEEE Frontiers in Education Conference. November 10 - 13, 1999 San Juan, Puerto Rico.

Soekirman. 2002. Perlu Paradigma Baru untuk Menanggulangi Masalah Gizi Makro di Indonesia. Guru Besar IImu Gizi/Kepala Pusat Studi Kebijakan Pangan dan Gizi. Institut Pertanian Bogor (IPB).

Straton CW, Jamila R. 2004. Strengthening Social and Emotional Competence in Young Children The Foudation for Early School Readines and Success. Infant and Young Children 17: 96-113.

Sussman MB, Steinmetz SK (ed). 1987. Handbook of Marriage and the Family. Plenum Press. New York and London.

Vandivere S, Moore KA, Zaslov M. 2000. Children's Family Environment, Findings from the National Survey of America's Family. [terhubung berkala]. http://www.childtrends.org.

Vela RH. 2003. The Role of Emotional Intelligence in the Academic Achievement of First Year College Students [disertasi]. Texas A\&M University-Kingsville.

Whetzel DL, McDaniel M. 2006. Prediction of National Wealth. Intelligence 34: 449-458.

Young, Ed. et al. 2003. Do K-12 School Facilities Affect Education Outcomes? The Tennessee Advisory Commission on Intergovernmental Relation, Tennessee. [terhubung berkala]. http://www. state.tn.us/tacir. 12/11/2007, 15:37.

Zaini et al. 2005. Effects of Nutritional Status on Academic Performance of Malaysian Primary School Children. Asia-Pacific of Public Health, Vol. 17, No. 2.

\footnotetext{
* Korespondensi :

Fakultas IImu Sosial dan IImu Politik Universitas Jendral Soedirman Jl. HR Bunyamin 993, Purwokerto 53122 Email : ignsuks_pwt@yahoo.com
} 